\title{
ALTERAÇÕES MORFOFISIOLÓGICAS DECORRENTES DO PROCESSO DE ENVELHECIMENTO DO SISTEMA MUSCULOESQUELÉTICO E SUAS CONSEQUENCIAS PARA O ORGANISMO HUMANO
}

\author{
Ana Paula Serra de Araújo \\ Fisioterapeuta/UNIPAR; Pós-graduada em Acupuntura/IBRATE; Pós-graduada em Fisioterapia em Terapia \\ Manual e Postural/CESUMAR; Mestre em Promoção da Saúde/UNICESUMAR \\ anaps_araujo@hotmail.com
}

\section{Sonia Maria Marques Gomes Bertolini}

Fiosioterapeuta/Faculdade de Educação Física de Lins; Mestre e Doutora eCiências Morfofuncionais/USP smmgbertolini.@yahoo.com.br

\author{
Joaquim Martins Junior \\ Profissional de Educação Física; Especialista em Educação Física/UEM; Mestre em Ciência do \\ Movimento/UFSM. Doutor em Educação/UNESP \\ jmjunior.@cesumar.br
}

\section{RESUMO}

Com o envelhecimento o sistema musculoesquelético vai se transformando progressivamente e passa a adquirir características estruturais e morfológicas específicas que prejudicam a capacidade funcional e física do indivíduo. $\mathrm{O}$ estudo tem como objetivo verificar e descrever as principais alterações morfofisiológicas decorrentes do processo de envelhecimento no sistema musculoesquelético e as suas consequências para o organismo. A literatura pesquisada evidência que a partir da $4^{\text {a }}$ década de vida ocorrer uma perda progressiva e absoluta da massa óssea, associada com alterações no tecido cartilaginoso, tendinoso e ligamentar, que se tornam mais rígidos, a massa muscular magra sofre descréscimo de 10\%-16\% após este período e a força muscular é reduzida em $15 \%$ por década após os 40 anos. Isso leva a uma diminuição da coordenação motora, da capacidade de realizar atividades de vida diária, podendo levar o idoso a um estado de impossibilidade física que influenciam negativamente na velocidade do caminhar, do subir escadas e do levantar-se da posição sentada para a em pé. Ao término do estudo, concluiu-se que entre as principais alterações do sistema musculoesquelético decorrentes do processo de envelhecimento são, a redução da massa óssea e muscular, associada a uma diminuição da força, potência, resistência e flexibilidade muscular.

Palavras-chave: Músculo; Envelhecimento; Idoso.

\begin{abstract}
With the aging of the musculoskeletal system is transformed and becomes progressively acquire specific structural and morphological characteristics that impair the physical and functional capacity of the individual. The study aims to determine and describe the main morphological and physiological changes resulting from the aging process in the musculoskeletal system and its consequences for the organism. The literature shows that from the 4th decade of life there is a progressive loss of bone mass and absolute, associated with changes in the cartilage tissue, tendon and ligament, which become more rigid, the descréscimo $10 \%-16 \%$ of muscle mass lean with $15 \%$ loss of muscle strength per decade after age 40 . This leads to a decrease in motor coordination, the ability to perform activities of daily living, the elderly can lead to a state of physical impossibility that negatively influence the speed of walking, climbing the stairs and getting up from a sitting position for at foot. At the end of the study, it was concluded that among the major changes of the musculoskeletal system resulting from the aging process is the reduction of bone and muscle mass, associated with a decrease in strength, power, muscular endurance and flexibility.
\end{abstract}

Keywords: Muscle, Aging, Elderly. 


\section{INTRODUÇÃO}

O estudo do envelhecimento e das suas consequências para o organismo humano, despertou nas últimas décadas o interesse de milhares de pessoas em todo o mundo, em especial daquelas que buscam formas de melhorar a qualidade de vida na terceira idade e de amenizar as consequências deletéricas do envelhecimento sobre o estado de saúde e bem-estar das pessoas.

Definido como um processo irreversível e inexorável a todos os indivíduos (BERNARDI; REIS; LOPES, 2008). O envelhecimento humano é caracterizado por alterações morfológicas, fisiológicas, bioquímicas e psicológicas que levam a uma diminuição da capacidade de adaptação do indivíduo ao meio ambiente, e consequentemente à morte (ALMEIDA; VALENTIM; DIEFENBACH, 2004; CIVINSKI; MONTIBELLER; BRAZ, 2011).

Marcado por um decréscimo das capacidades motoras, da redução da força, flexibilidade, velocidade, e níveis de volume de oxigênio máximo $\left(\mathrm{VO}_{2}\right.$ máx), que dificultam a realização de atividades de vida diária (AVD), e a manutenção de um estilo de vida saudável (CIVINSKI; MONTIBELLER; BRAZ, 2011).

O envelhecimento é um processo biológico normal que se encontra associado a inúmeras alterações nos diferentes sistemas corporais existentes (cardíaco, respiratório, musculoesquelético e hormonal) (RIBEIRO; ALVES; MEIRA, 2009; FECHINE; TROMPIERI, 2012).

Entre os diferentes sistemas corporais existentes, o sistema musculoesquelético é um dos que mais influência de forma significativa a qualidade de vidas das pessoas idosas.

Com o processo de envelhecimento normal o sistema musculoesquelético vai se transformando progressivamente e passa a adquirir características estruturais e morfológicas especificas que fazem com que ele perca: força e massa muscular (ALMEIDA; VALENTIM; DIEFENBACH, 2004).

Neste contexto, o estudo tem como objetivo verificar e descrever as principais alterações morfofisiológicas decorrentes do processo de envelhecimento no sistema musculoesquelético e as suas consequências para o organismo.

\section{METODOLOGIA}

O presente estudo trata-se e uma pesquisa qualitativa do tipo revisão de literatura sistemática.

A revisão sistemática da literatura é um estudo secundário, que tem por objetivo reunir estudos semelhantes, publicados ou não, avaliando-os criticamente em sua metodologia e reunindoos em uma análise estatística, a metanálise, quando isto é possível. Por sintetizar estudos primários semelhantes e de boa qualidade é considerada o melhor nível de evidência para tomadas de decisões em questões sobre terapêutica (ATALLAH; CASTRO, 1998).

Para a realização do estudo a busca dos artigos se deu no período compreendido entre abril e junho de 2013, por intermédio de pesquisa online. 
Para inclusão dos artigos no estudo, os critérios definidos foram: artigos originais, teses, dissertações disponibilizados no portal da Scientific Eletronic Library Online (SCIELO) e Google Acadêmico (www.scholar.google.com.br), publicados no idioma português, disponibilizados na integra e de forma gratuita, que abordavam a temática proposta e que respondiam a seguinte questão norteadora: Quais as alterações morfofisiológicas decorrentes do processo de envelhecimento do sistema musculoesquelético e quais são suas consequências para o organismo humano?

O recorte temporal utilizado para a realização deste estudo e foi o de 1999 a 2012 e como estratégia de busca na SciELO e Google Acadêmico utilizou-se os seguintes descritores cruzados: músculo, sistema musculoesquelético, alterações morfofisiológicas, envelhecimento e idoso.

A seleção do material obtido foi efetuada em cinco etapas. A primeira foi caracterizada pela pesquisa do material nas bases de dados eletrônicos. A segunda compreendeu a leitura dos títulos e resumos dos trabalhos, visando uma maior aproximação e conhecimento, sendo excluídos os que não tivessem relação e relevância com o tema. Após essa seleção, iniciou-se a terceira etapa, na qual buscou-se os textos completos que se encontravam disponíveis na íntegra e forma gratuita, sendo estes, inclusos na revisão. A quarta etapa constituiu-se de leitura e transcrição e seleção das informações relevantes para o estudo; a quinta e última etapa constituiu-se da transcrição e discussão das informações obtidas nas publicações arroladas, foram divididas sequencialmente nos seguintes itens: sistema musculoesquelético, osso, tecido cartilaginoso, tendinoso e ligamentar e tecido adiposo.

Após a obtenção dos artigos nos sítios eletrônicos, os mesmo foram submetidos à leitura, análise das informações relevantes, transcrição das informações relevantes para o estudo e discussão.

Adicionalmente foi feito consulta em livros acadêmicos sobre o sistema musculoesquelético disponibilizados na biblioteca do Centro Universitário Cesumar (UNICESUMAR) para complementação das informações sobre as alterações morfofisiológicas no sistema musculoesquelético decorrentes do envelhecimento.

\section{RESULTADOS}

Utilizando o cruzamento dos descritores no portal ScIELO e Google Acadêmico, foram encontrados 46 publicações, sendo selecionados para a realização do presente estudo 22 artigos, os quais atenderam aos critérios de inclusão e a questão norteadora.

Com relação aos artigos selecionados, estes tiveram suas informações transcritas em seis itens ja mencionados sendo eles sistema musculoesquelético, osso, tecido cartilaginoso, tendinoso e ligamentar e tecido adiposo. Posteriormente as informações transcritas para estes itens foram submetidas a analise e discussão a qual é apresentada a seguir.

\section{DISCUSSÃO}

\subsection{O sistema musculoesquelético}

Morfologicamente o sistema musculoesquelético é composto por ossos, músculos, ligamentos, tendões, articulações e tecido gorduroso que, no seu conjunto, sustentam e dão mobilidade ao corpo. 


\subsection{Osso}

Os ossos são estruturas sólidas, pouco flexíveis que dão sustentação ao corpo. Formados por células denominadas de osteoblastos e osteoclastos, minerais (cálcio e fósforo) e matriz orgânica (proteínas colágenas e não-colágenas) (CAMPOS, 2003).

A matriz orgânica do osso segundo explicações de Guyton e Hall (1997) é constituída entre $90 \%$ e $95 \%$ por fibras colágenas que se estendem primariamente ao longo da linha de força de tensão presente nos ossos; ao passo que o restante do osso é constituído por um meio gelatinoso homogêneo denominado de substância fundamental, que por sua vez, é composta de líquido extracelular e proteoglicanos (condroitinos, sulfato e ácido hialurônico).

De acordo com Campos (2003) e Ribeiro, Alves e Meira (2009) o tecido ósseo pode vir a ser visto como um sistema orgânico em constante remodelação, por ser formado por células formadoras de tecido ósseo (osteoblastos - que sintetizam e mineralizam a matriz proteica com cristais de hidroxiapatita) e por células de reabsorção de tecido ósseo (osteoclastos - que promovem a reabsorção óssea, mantendo assim, uma constante remodelação tecidual, que é regulada pelos hormônios da paratireóide (PTH) e vitamina D entre outros compostos, que dão origem a dois tipos de ossos: trabecular ou esponjoso e cortical ou compacto.

O osso trabecular, encontrado principalmente nas vértebras, crânio, pélvis e porção ultradistal do rádio apresenta maior taxa metabólica e suscetibilidade a alterações da sua massa mineral do que o osso cortical, que é encontrado sobre tudo nos ossos longos, colo femoral e radio distal (CAMPOS et al., 2003).

Fisiologicamente, acredita-se que durante as duas primeiras décadas de vida, há um predomínio de formação de tecido ósseo e consequente incremento progressivo de massa mineral óssea até a $4^{\text {a }}$ década de vida. Período no qual o indivíduo atinge o seu "pico máximo de massa óssea" durante o seu desenvolvimento corporal (RIBEIRO; ALVES; MEIRA, 2009).

A partir da $4^{a}$ década de vida segundo Assumpção, Souza e Furtado (2008) e Ribeiro, Alves e Meira (2009) o número total de osteoblastos presentes no osso passa a diminuir, ao passo que a atividade dos osteoclastos aumenta ou se mantém igual. Consequentemente, passa a ocorrer uma perda progressiva e absoluta de massa óssea no corpo, denominada de "osteopenia fisiológica".

Essa perda de massa óssea durante o processo de envelhecimento normal tende a ocorrer em todas as pessoas independente do gênero (masculino ou feminino), e especialmente após os 50 anos de idade (FECHINE; TROMPIERI, 2012).

Complementando o relatado Assumpção, Souza e Furtado (2008), explicam que de um modo geral durante o processo de envelhecimento, a perda de massa óssea tem início entre a $5^{\mathrm{a}}$ e $6^{\mathrm{a}}$ década de vida no homem, com uma perda de $0,3 \%$ ao ano, e na mulher a uma taxa de $1 \%$ ao ano dos 45 aos 75 anos de idade. Além da influência da ação dos osteoblastos e osteoclastos anteriormente mencionada, durante o envelhecimento a perda de massa mineral óssea, também sofre influência de hormônios em especial dos hormônios sexuais (testosterona e progesterona).

Conforme Bernardi, Reis e Lopes (2008) após os 50 anos de idade há decréscimo entre 0,4\% e $0,85 \%$ na produção de hormônios sexuais masculinos e femininos ao ano, podendo tal redução chegar a $65 \%$, quando coparada a taxa hormonal de um adulto jovem com a de um idoso com 75 anos de idade. Esta redução na produção de hormônios sexuais, além de ocasionar em uma perda da massa mineral óssea também gera diminuição da qualidade de vida sexual, da massa e força muscular no idoso. 
$\mathrm{Na}$ tabela 1, é possível visualizar as principais alterações morfológicas e fisiológicas que ocorrem no tecido ósseo durante o processo de envelhecimento, já citadas. Nesta tabela fica evidente, que entre as principais alterações neste tecido temos a perda de massa mineral óssea.

Tabela 1. Principais alterações morfológicas e fisiológicas decorrentes do processo de envelhecimento no tecido ósseo.

- $\quad$ Perda de massa mineral óssea;

- Desequilíbrio do processo de reabsorção de cálcio;

- Desmineralização constante da massa e da densidade óssea o que se traduz numa maior

- Fagilidade óssea.

Fonte: Elaborado pelo próprio autor do estudo, com base em: Nóbrega et al. (1999, p.209), Assumpção, Souza e Furtado (2008 p.456); Rossi (2008, p.8); e Ribeiro, Alves e Meira (2009, p.223).

Em decorrência das informações anteriormente elucidadas, e apresentadas na tabela 1, tornase necessário ressaltar que a perda de massa mineral óssea durante o processo de envelhecimento também é influenciada por: deficiências alimentares, falta de exercício físico e alterações naturais do organismo (FECHINE; TROMPIERI, 2012).

Em virtude destes fatos é possível crer que as alterações no tecido ósseo decorrentes do processo de envelhecimento, podem ser evitadas ou desaceleradas por meio de um tratamento clínico adequado; da prática regular de atividade física, em associação com uma alimentação balanceada e rica em vitamina D e cálcio (TEIXEIRA \& PEREIRA, 2010).

\subsection{Tecido cartilaginoso, tendinoso e ligamentar}

Associada às alterações da massa mineral óssea, durante o envelhecimento é possível notar também alterações no tecido cartilaginoso, tendinoso e ligamentar.

O tecido cartilaginoso, conforme Ribeiro, Alves e Meira (2009) é um tipo especial de tecido conjuntivo que ajuda o movimento da articulação; este tecido é constituído por camadas de células (condrócitos), e por uma membrana que secreta um líquido lubrificante composto por água, fibras colágenas e proteoglicanas, denominado líquido sinovial. Já os tendões e ligamentos são compostos por tecido conjuntivo denso.

O líquido sinovial é um dialisado do plasma viscoso, produzido pela membrana sinovial, com função de lubrificação, nutrição, auxiliando no suporte mecânico e na absorção de impacto. Ele é livre de material floculento ou fragmentos, possui coloração de clara à palha amarelada, e contém hialuronato, eletrólitos, glicose, proteínas e enzimas[...]. O líquido sinovial normal contém aproximadamente $30 \%$ do valor da proteína plasmática, sendo o conteúdo protéico normalmente menor que 2,5g dL (MARTINS; SILVA; BACCARIN, 2007, p.785).

Com o envelhecimento, na cartilagem articular passa a ocorrer, uma diminuição na produção de líquido sinovial e afinamento do tecido cartilaginoso, e em conjunto os tendões e ligamentos tendem a se tornar mais curtos e menos flexíveis, resultando em menor amplitude de movimento articular (ADM) nas das articulações afetadas. Este processo conforme Ribeiro, Alves e Meira (2009) acomete preferencialmente as articulações sinoviais livremente móveis (ou diartroses), como as articulações dos joelhos, pulsos, cotovelos e dos quadris, as quais também são as mais afetadas durante o processo de envelhecimento.

De acordo com Nóbrega et al. (1999), após os 35 anos de idade há uma alteração natural da cartilagem articular que, associada às alterações biomecânicas adquiridas ao longo da vida do indivíduo ou não, provocam degenerações diversas que podem levar à diminuição da função 
locomotora e da flexibilidade, acarretando maior risco de lesões para o idoso. Durante todo o processo de envelhecimento, os discos interverbrais, assim como a cartilagem articular também passam a perder uma porção do seu conteúdo de líquido (água) o qual é importante para a absorção de choques, tornando-se então uma estrutura mais fibrososa.

Na tabela 2, é possível visualizar facilmente todas essas alterações que ocorrem no tecido cartilaginoso, tendinoso e ligamentar durante o processo de envelhecimento normal.

Tabela 2. Principais alterações morfológicas e fisiológicas no tecido cartilaginoso, tendinoso e ligamentar decorrentes do processo de envelhecimento normal.

- $\quad$ Desidratação do disco intervertebral;

- Redução do volume e da qualidade do líquido sinovial;

- Calcificação e ossificação dos ligamentos;

- Redução da amplitude de movimento articular.

Fonte: Elaborado com base nos autores Nóbrega et al. (1999, p.209) e Rossi (2008, p.8- 9), Ribeiro, Alves e Meira (2009, p.223).

Fica evidente nas informações apresentadas na tabela 2, que todas as alterações ali apresentadas ao serem combinadas com as alterações de densidade mineral óssea, em especial das vértebras ocasionam na compressão dos discos, que, por sua vez, acabam por influência a diminuição da altura e do peso corporal nos idosos (FECHINE; TROMPIERI, 2012).

Estudos realizados nos últimos anos também tem mostrado que o envelhecimento no sistema musculoesquelético não se encontra apenas associado às alterações anteriormente apresentadas, mas que também se encontra associado a uma diminuição do índice de massa corporal no idoso, que acaba por levar a uma diminuição da capacidade funcional do individuo na velhice como veremos a seguir.

\subsection{Tecido musculoesquelético}

Guyton e Hall (1997) relatam que cerca de $40 \%$ do corpo humano é constituído por tecido musculoesquelético, e que talvez outros $10 \%$ seja constituído por músculo liso e cardíaco. Corroborando com este relato Rossi (2008) afirma que o músculo esquelético é a maior massa tecidual do corpo humano.

De acordo com Assis e Rabelo (2008) o músculo estriado esquelético é constituído por estruturas que movem os segmentos do corpo por encurtamento da distância que existe entre suas extremidades fixadas, ou seja, por contração. Porém, a musculatura não assegura só a dinâmica do movimento corpóreo, assegura também a estática do corpo humano.

Histologicamente Boff (2008) menciona que as fibras musculares são envolvidas por uma membrana plasmática chamada de sarcolema; e que abaixo do sarcolema existe outra membrana denominada de basal que é formada por proteínas e filamentos de colágeno.

As proteínas segundo Souto, Bandeira e Sandoval (2010) correspondem habitualmente a $15 \%$ de todos os componentes do organismo humano; e são responsáveis não só pela constituição das estruturas que formam os órgãos, tecidos e enzimas do corpo, como também são componentes importantes dos sistemas bioquímicos de produção de energia corporal.

Já o colágeno no músculo estriado esquelético desempenha função estrutural, ligando as fibras musculares, de modo a garantir um alinhamento apropriado dessas, a fim de permitir que o músculo funcione como uma unidade única. Além é claro, de fazer com que as forças de contração 
muscular sejam efetivamente transmitidas aos ossos e as articulações (IAMAMURA; IAMAMURA; HIROSE-PASTOR, 1999).

Guyton e Hall (1997) e Boff (2008) relatam que estruturalmente as fibras musculares são constituídas por sarcômeros, dentro dos quais se localizam filamentos proteicos finos e grossos formados por actina, tropomiosina, troponina e tropomodulina, que tem como função permitir a contração muscular. Ao passo que as fibras que compõem o músculo estriado esquelético podem ser classificadas em fibras de contração lenta (tipo I), e rápida (Tipo II).

Segundo Boff (2008) as fibras do tipo I geram energia utilizando o sistema aeróbio, possuem menor velocidade de propagação do cálcio; grande número de mitocôndrias, sendo, portanto, muito resistentes à fadiga. Haja vista, que no sistema aeróbio o oxigênio $\left(\mathrm{O}_{2}\right)$ funciona como fonte de queima dos substratos que produzirão a energia (Adenosina trifosfato - ATP) transportada para o músculo em atividade, durante a realização de exercícios de longa duração, contínuos de baixa e/ou moderada intensidade como por exemplo: caminhada, corrida, e natação.

Já no sistema anaeróbio a atividade muscular exige uma contração muscular contra a resistência, e utiliza uma fonte de energia que independe do uso de $\mathrm{O} 2$, basicamente o exercício realizado é de alta intensidade e de curta duração, como é o caso da musculação (DOMICIANO; ARAÚJO; MACHADO, 2010).

Boff (2008) relata ainda que as fibras do tipo I recebem maior vascularização, tem altos níveis de mioglobina, baixa velocidade de contração, relaxamento e baixa capacidade para gerar força muscular. Em contrapartida, apresentam ao longo tempo de contração, predomínio de enzimas oxidativas (citrato sintetase e succinato desidrogenase). Ao passo que as fibras do tipo II, geram energia a partir do sistema anaeróbio, têm maior velocidade de contração muscular, pouco tempo de contração (resistência), predomínio das enzimas glicolíticas (fosfofrutoquinase - PFK, e lactato desidrogenase - LDH), suas fibras podem ainda ser consideradas como intermediárias, ficando entre lentas e rápidas.

As alterações no predomínio de um ou outro tipo de fibra muscular servem como base fisiológica para numerosas intervenções destinadas a aumentar o desenvolvimento da força e da sustentação muscular. Para este mesmo autor tal predomínio também poder vir a ser responsável por algumas das alterações ou disfunções vistas em indivíduos que ficaram sujeitos a grandes períodos de imobilidade, inatividade, desenervação muscular, e em idosos (BOFF, 2008).

Ł̀ sabido que com o processo de envelhecimento, a estrutura e função do sistema musculoesquelético é alterada, e entre todas as estruturas que compõem este sistema a que mais sente estas alteração é de o músculo estriado esquelético. Estruturalmente, a massa muscular diminui à medida que a número e o tamanho das fibras musculares declina durante o final da meia idade e dos anos posteriores a vida adulta (GALLAHUE; OZMUN, 2001).

Sobre este assunto autores como Fechine e Trompieri (2012) relatam que no período compreendido entre os 25 e 65 anos de idade, passa a ocorrer no organismo humano uma diminuição de $10 \%$ a $16 \%$ da massa muscular magra (massa livre de gordura). De acordo com estes mesmos autores até os 30 anos de idade o indivíduo atinge o seu pico "máximo de massa muscular" que na maioria das pessoas é mantido de modo constante até os 40 anos de idade, e após esta idade passa a sofrer um decréscimo acelerado.

Segundo Unicovsky (2004), Rossi (2008) e Lacout e Morini (2006) essa perda de massa magra pode chegar a 50\% (dos 20 aos 90 anos) ou $40 \%$ (dos 30 aos 80 anos). Assim, na medida em 
que envelhecemos nosso corpo passa a sofrer com uma lenta e progressiva redução da massa muscular magra, que paulatinamente, vai sendo substituída por colágeno e gordura.

Com a perda de massa muscular magra surge no organismo humano, uma série de alterações e déficits funcionais e orgânicos, dentre os quais se destaca: a diminuição da força muscular, déficit de coordenação motora e da capacidade de realização de AVD e atividades laborais; redução da flexibilidade, atrofia muscular, deteriorização de músculos, tendões e ligamentos, redução do peso corporal entre outras alterações conforme mostra a tabela 3.

Tabela 3. Principais alterações do sistema musculoesquelético presentes no tecido muscular decorrentes do processo de envelhecimento normal e as suas consequências para o organismo do idoso.

\begin{tabular}{|c|c|}
\hline Alterações do sistema musculoesquelético & Consequencias \\
\hline $\begin{array}{l}\text { - Diminuição das proteínas contrateis; } \\
\text { - Substituição de tecido muscular por tecido conjuntivo e } \\
\text { adiposo; } \\
\text { - Diminuição da área transversal relativa das fibras tipo II; } \\
\text { - Diminuição do aporte sanguíneo, da densidade; } \\
\text { mitocondrial e da atividade das enzimas oxidativas; } \\
\text { - Atrofia lenta e constante dos músculos do tronco e das } \\
\text { extremidades; } \\
\text { - Perda de potencia, força e agilidade; } \\
\text { - Aumento da taxa de gordura no interior dos músculos; } \\
\text { - Diminuição no peso dos músculos entre os } 30 \text { e } 70 \text { anos; } \\
\text { - Diminuição das reservas de glicogênio muscular. }\end{array}$ & $\begin{array}{ll}\text { - } & \text { Fraqueza muscular; } \\
\text { - } & \text { Lentidão dos movimentos; } \\
\text { - } & \text { Limitações funcionais; } \\
\text { - } & \text { Diminuição da amplitude de movimento } \\
& \text { articular; } \\
\text { - Encurtamentos musculares. }\end{array}$ \\
\hline
\end{tabular}

A perda de massa muscular magra associada à idade anteriormente citada e evidenciadas na tabela 3, chamada de sarcopenia, na concepção de Unicovsky (2004) ocorre em associação com a perda de massa óssea, com a redução da sensibilidade à insulina; redução da capacidade aeróbia, da taxa basal, da força muscular e do nível de atividade física praticado pelo individuo idoso.

De acordo com Fechine e Trompieri (2012) com o declínio da massa muscular, durante o processo de envelhecimento há também uma perda progressiva da força e resistência muscular.

Pesquisas atuais apontam que a força muscular durante o processo de envelhecimento normal é reduzida em aproximadamente $15 \%$ entre a $6^{\mathrm{a}}$ e $7^{\mathrm{a}}$ década de vida, e em $30 \%$ após este período.

Conforme Orsatti et al. (2011) após a $7^{a}$ década de vida o avanço progressivo desta perda de força muscular pode levar o idoso a um estado de impossibilidade física, que impossível a realização de atividades comuns da vida diária, como por exemplo: levantar-se da cadeira, subir escadas, varrer o chão ou tomar banho. O que por sua vez, acaba contribuindo expressivamente para o desenvolvimento da fragilidade e diminuição funcional.

Fechine e Trompieri (2012) durante o desenvolvimento humano o "pico de força muscular" é atingido por volta dos 30 anos de idade, e depois dessa idade, passa a ocorrer uma redução na secção transversal do músculo, com maior acúmulo de colágeno ocasionando em atrofia muscular e consequente perda de força de contração muscular.

Diferentes autores têm referido que a atrofia e fraqueza muscular associadas ao envelhecimento são aspectos determinantes na morbidade e mortalidade de pessoas idosas. 
Para Carvalho e Soares (2003) essa perda de força e da massa muscular predispõe os idosos a uma limitação funcional. Tornando então estas alterações fatores predisponentes para muitos dos processos patológicos associados ao aumento da morbilidade e mortalidade na terceira idade.

Corroborando com tal relato, Orsatti et al. (2011) explica que as reduções da massa e força muscular são maiores nos membros inferiores do que nos superiores, e que tais reduções influenciam negativamente na velocidade do caminhar, do subir escadas e do levantar-se da posição sentada para a em pé, por exemplo.

No aparelho locomotor, a deterioração funcional que ocorre com o progredir da idade envolve alterações morfológicas e bioquímicas especificas. Dessa forma, a atrofia muscular concomitante o aumento dos tecidos conjuntivo e gorduroso parece atingir com maior intensidade as fibras musculares de contração rápida do que as fibras musculares de contração lenta (IMAMURA; IMAMURA; HIROSE-PASTOR, 1999). Outras alterações do envelhecimento incluem a perda da massa muscular sem gordura, o declínio da força muscular absoluta e a redução do uso de determinados grupos musculares.

De acordo com Alfiere e Moura (2008) a redução da utilização de determinados grupos musculares, determina no idoso a queda no desempenho muscular, que por sua vez, é evidenciada pela menor resistência à fadiga e prejuízo na coordenação motora fina e na velocidade dos movimentos corporais.

Como o sistema musculoesquelético é responsável pelas ações de contração vigorosas, e das contrações que desempenham um papel fundamental no controle postural. Em consequência da perda de fibras musculares, da redução de neurônios motores e unidades motoras, da força e massa muscular que ocorrem durante o processo de envelhecimento este sistema passa a ter uma diminuição da sua funcionalidade de estabilidade (ALFIERE; MOURA, 2008). Como isso, passam a ocorrer alterações posturais, como a cifose, a redução da lordose, o valgismo nos quadris e o alargamento da base de apoio, que em associação levam um padrão postural visto como típico do indivíduo idoso (UNICOVSKY, 2004).

Com base nos fatos anteriormente relatados, temos que o envelhecimento normal, associado às inúmeras alterações do sistema musculoesquelético, geram repercussões na funcionalidade, mobilidade, autonomia, saúde e qualidade de vida da população idosa. Pois, a capacidade de realizar diferentes atividades diárias, atividades laborais ou recreacionais é determinada, em grande parte, pela capacidade de desenvolver força muscular (CARVALHO; SOARES, 2004).

Todavia, torna-se necessário ressaltar que a perda de função muscular não se da apenas devido à substituição das fibras musculares e pela atrofia musculares, já bastante elucidadas ao longo do texto. Ela se dá também devido ao nível de capilarização dos músculos, que no idoso em comparação ao individuo jovem, encontra-se reduzido é reduzido (ALFIERE; MOURA. 2008). Além disso, as alterações no músculo estriado esquelético decorrentes do envelhecimento, também são fortemente influenciadas por fatores hormonais, assim como o ocorrido no tecido ósseo.

Para Alfiere e Moura (2008) a diminuição do fator de crescimento (GH) e do fator insulínico de crescimento (IGF-1), também contribui para o declínio da capacidade funcional do idoso.

Com relação à atrofia das fibras musculares autores como Carvalho e Soares (2004), relatam que esta atrofia tem início aos 25 anos de idade, e que posteriormente passa a sofre de um declínio de $10 \%$ a cada década até os 50 anos. Após este período como as demais alterações já mencionadas 
ela passa a ocorrer de modo mais pronunciado podem atingir até $50 \%$ da área de secção transversal dos músculos aos 80 anos de idade.

Acredita-se que o envelhecimento seja responsável por perda da quantidade de motoneurônios $\alpha$. Assim, indivíduos idosos apresentariam menores quantidades de unidades motoras (UM). Isso provocaria uma degeneração dos elementos neurais, reorganização dos componentes restantes, variações na proporção dos diferentes tipos de UM e alterações na propriedade de unidades cada UM, que com o avançar da idade contribuiria para a formação do quadro de atrofia da musculatura estriada esquelética (LACOURT; MARINI, 2006).

A densidade capilar e o aporte sanguíneo reduzidos, durante o processo de envelhecimento ocasionam em um comprometimento do transporte de glicose; em uma menor densidade mitocondrial; em uma diminuição da atividade das enzimas oxidativas e a taxa de repleção de fosfocreatina; que acaba por contribuir para o decréscimo na resistência muscular verificada em pessoas com idade avançada (LACOURT \& MARINI, 2006).

\subsection{Tecido Adiposo}

Como já mencionado durante a meia-idade, ocorre aumento da massa corporal magra, entretanto na velhice, ocorre uma substituição da massa muscular magra por tecido adiposo.

De acordo com Fiori et al. (2006) com o envelhecimento, o peso e a estatura corporal tendem a diminuir, bem como a massa magra. Há aumento de tecido gorduroso na região abdominal e diminuição desse tecido na região dos braços.

Dos 15 aos 98 anos de idade, a massa de gordura por década aumenta numa proporção maior para as mulheres, com valores situados em torno de $1,7 \%$, enquanto que para os homens esse valor situa-se em $1,5 \%$. A nível corporal esta substituição de tecido faz com que a tecido adiposo seja depositado em maior quantidade no tronco e ao redor de órgãos viscerais, enquanto que a gordura subcutânea aumenta levemente (FECHINE; TROMPIERI, 2012).

Para Fernandes (2011) este aumento na gordura corporal e redução do tecido muscular, no idoso ocorrem, principalmente, em virtude da diminuição da atividade física e da taxa metabólica basal do indivíduo.

Tais alterações na estrutura e forma corporal acima relatadas e apresentadas ao longo do texto, geram também importantes alterações dentro da estrutura esquelética que surge na medida em que o indivíduo envelhece, como é o caso da redução da estatura, decorrente da desidratação do disco intervertebral, mau alinhamento da coluna vertebral, má postura e enfraquecimento dos músculos que apoiam a coluna e o tórax (GUYTON; HALL, 1997; FERNANDES, 2011).

\section{CONSIDERAÇÕES FINAIS}

Constatou-se que as alterações no organismo no sistema musculoesquelético em função do envelhecimento são normais e naturais.

No entanto, alguns fatores podem ser associados à possibilidade de redução dessas perdas e manutenção da saúde física dos idosos como é o caso da realização de uma alimentação balanceada e da pratica regular de atividade física, que podem contribuir para a manutenção do tecido muscular e ósseo em um bom nível funcional. 
No caso do sistema musculoesquelético a perda de conteúdo mineral ósseo, de massa e força muscular, embora passiveis de prevenção geram déficits funcionais importantes para o idoso que podem vir a comprometer a sua qualidade de vida. Fazendo então com haja a necessidade de elaboração de estratégias de intervenção que conscientize a população sobre a importância de se prevenir tais alterações ao longo da vida.

Conclui-se que as principais alterações encontradas no sistema musculoesquelético decorrentes do processo de envelhecimento normal são: a redução da massa óssea e muscular, diminuição da força, potência, resistência e flexibilidade muscular.

\section{REFERÊNCIAS}

ALFIERI, F. M.; MORAES, M. C. L. Envelhecimento e controle postural. Revista Saúde Coletiva, Barueri, v.4, n.19, p.30-33, out.-dez. 2008.

ALMEIDA, S. T.; VALENTIM, A. L.; DIEFENBACH, N. Lian Gong como prática fisioterápica preventiva do envelhecimento. Estudos interdisciplinares do Envelhecimento, Porto Alegre, v.6, n.1, p.103-110, jan. 2004.

ASSIS, E. L.; RABELO, H. T. Percepção da capacidade funcional de mulheres idosas praticantes de hidroginástica. MOVIMENTUM - Revista Digital de Educação Física, Ipatinga, v.1, n.3, p.110, ago.-dez. 2006. Disponível em:<www.movimentun.com.br>. Acesso em: 05 mar. 2012.

ASSUMPÇÃO, C. O.; SOUZA, T. M. F.; FURTADO, C. B. Treinamento resistido frente ao envelhecimento: uma alternativa viável e eficaz. Anuário da Produção Acadêmica Docente. São Paulo, v.2, n.3, p.451-476, ago. 2008.

BERNARDI, D. F.; REIS, M. A. S.; LOPES, N. B. O tratamento da sarcopenia através do exercicio de força na prevenção de quedas em idosos: revisão de literatura. Ensaios e Ciência: Ciências Biológicas, Agrárias e da Saúde, Valinhos, v.12, n.2, p.197-213, jun. 2008.

BOFF, S. R.; A fibra muscular e fatores que interferem no seu fenótipo. Acta Fisiatrica, São Paulo, v.15, n.2, p.111-116, jun. 2008.

CAMPOS, L. M. A. Osteoporose na infância e na adolescência. Jornal de Pediatria, Porto Alegre, v.6, n.79, p.481-488, ago. 2003.

CARVALHO, J.; SOARES, J. M. C. Envelhecimento e força muscular - breve revisão. Revista Portuguesa de Ciências do Desporto, Porto, v.4, n.3, p.79-93, ago. 2004.

CIVINSKI, C.; MONTIBELLER, A.; BRAZ, A. L. O. A Importância do exercício físico no envelhecimento. Revista da Unifebe, São Paulo, v.9, n.1, p. 163-175, jan. 2011. Disponível em: <http://www.unifebe.edu.br/revistadaunifebe/2011/artigo028.pdf>.Acesso em: 05 mar. 2012.

DOMICIANO, A. M. O.; ARAÚJO, A. P. S.; MACHADO, V. H. R. Treinamento aeróbio e anaeróbio: uma revisão. UNINGÁ Review, v.1, n. 3, p. 71-80, abr. 2010. Disponível em: $<$ http://www.uningareview.com.br/adm/uploads/00ecc277aa36f7986537917fafdaef61 .pdf>. Acesso em: 12 mar. 2012. 
FECHINE, B. R. A.; TROMPIERI, N. O processo de envelhecimento: as principais alterações que acontecem com o idoso com o passar dos anos. InterSciencePlace, Rio de Janeiro, v.1, n.20, p.106194, jun. 2012.

FERNANDES, P. M. Indicadores nutricionais no envelhecimento: um desafio para o diagnóstico nutricional precoce. Revista Eletrônica Novo Enfoque, São Paulo, v. 12, n. 12, p. 15-22, mar. 2011. Disponível em:

http://www.castelobranco.br/sistema/novoenfoque/files/12/artigos/03.pdf>. Acesso em: 12 mar.2012.

FIORE, E. G. et al. Perfil nutricional de idosos frequentadores de unidade básica de saúde. Revista Ciências Médicas, Campinas, v.15, n.5, p.369-377, set.-out. 2006.

GALLAHUE, D. L.; OZMUN, J. C. Compreendendo o desenvolvimento motor: bebês, crianças, adolescentes e adultos. São Paulo: Phorte editora, 2001, 641p.

GUYTON, A. C.; HALL, J. E. Tratado de fisiologia médica. 9. ed. Rio de Janeiro: Manole. 1997.

IMAMURA, S. T.; IMAMURA, M.; HIROSE-PASTOR, E. Efeitos do envelhecimento e do exercício físico sobre o colágeno do músculo esquelético humano. Revista Brasileira de Reumatologia, São Paulo, v. 39, n.1, p. 68-82, jan.-fev. 1999.

LACOURT, M. X.; MARINI, L. L. Decréscimo da função muscular decorrente do envelhecimento e a influência na qualidade de vida do idoso: uma revisão de literatura. Revista Brasileira de Ciências do Envelhecimento Humano, Passo Fundo, v. 1, n.1, p.114-121, jan.-jul. 2006.

MARTINS, E. A. N.; SILVA, L. C. L. C.; BACCARIN, R. Y. A. Líquido sinovial da articulação femuropatelar após desmotomia patelar medial experimental em equinos. Ciência Rural, Santa Maria, v.37, n.3, p.784-788, mai.-jun. 2007.

NÓBREGA, A. C. L. et al. Posicionamento Oficial da Sociedade Brasileira de Medicina do Esporte e da Sociedade Brasileira de Geriatria e Gerontologia: Atividade Física e Saúde no Idoso. Revista Brasileira de Medicina do Esporte, Curitiba, v. 5, n. 6, p. 207- 211, nov.-dez. 1999.

ORSATTI, F. L. et al. Redução da força muscular está relacionada à perda muscular em mulheres acima de 40 anos. Revista Brasileira de Cineantropometria e Desempenho Humano, Florianópolis, v.13, n.1, p.36-42, jan. 2011.

RIBEIRO, L. C. C.; ALVES, P. B.; MEIRA, E. P. Percepção dos idosos sobre as alterações fisiológicas do envelhecimento. Ciência, Cuidado e Saúde, Maringá, v.8, n.2, p.220-227, abr.-Jun. 2009.

ROSSI, E. Envelhecimento do sistema osteoarticular. Einstein, São Paulo, v.6, 1S, p. 7-12, jun. 2008.

SOUTO, P. P. C.; BANDEIRA, T. F.; SANDOVAL, R. A. Força muscular de membros superiores e inferiores: estudo correlacional e comparativo entre grupos de idosas. TRANCES: Revista de Transmisión del Conocimiento Educativo y de La Salud, Sevilla, v.3, n.1, 129-148, jan. 2010.

TEIXEIRA, C. S.; PEREIRA, É. F. Alterações morfológicas associadas ao envelhecimento humano. Lecturas Educación Física y Deportes, Buenos Aires, v.1, n.1, p.1-1, jan. 2010. 
Disponível em: < http://www.efdeportes.com/efd124/alteracoesmorfofisiologicas- associadas-aoenvelhecimento-humano.htm >. Acesso em: 10 mar. 2012.

UNICOVSKY, M. A. R. Idoso com sarcopenia: uma abordagem do cuidado da enfermeira. Revista Brasileira de Enfermagem, Brasília, v.57, n.3, p. 298-302, mai.-jun. 2004. 